\title{
Towards an Accessible Information Society in Europe
}

The European Commission considers it is now urgent to achieve a more coherent, common and effective approach to e-accessibility, in particular web accessibility, to hasten the advent of an accessible information society. Document COM (2008) 804 Final. This is based on the conclusion that "as our society is evolving to an 'information society,' we are becoming intrinsically more dependent on technology-based products and services in our daily lives. Yet poor e-accessibility means many Europeans with a disability are still unable to access the benefits of the information society."

E-accessibility involves overcoming the technical barriers and difficulties that people with disabilities, including many elderly people, experience when trying to participate on equal terms in the information society.

If everyone is to have equal opportunities for participation in today's society, the full range of ICT goods and services need to be accessible. This includes computers, telephones, TVs, online government, online shopping, call centers, self-service terminals such as automatic teller machines (ATMs) and ticket machines.

To achieve a common and coherent e-accessibility approach the Commission recommends:

- European Standardization Organizations (ESOs) should pursue wider e-accessibility standardization activities to reduce market fragmentation and facilitate increased adoption of ICT-enabled goods and services.

- Member States, stakeholders and the Commission should stimulate greater levels of innovation and deployment in e-accessibility, in particular through the use of the EU research and innovative programs and the Structural Funds.

- All stakeholders should make full use of the opportunities to address e-accessibility within existing EU legislation. The Commission will include ap- propriate e-accessibility requirements in revisions or new legislation developments.

- The Commission will boost stakeholder cooperation activities to enhance the coherence, coordination and impact of the actions, in particular, a new high-level ad-hoc group will be mandated to provide guidance on the overall coherent approach to e-accessibility (including web accessibility) and propose priority actions to overcome e-accessibility barriers.

To speed up progress is the special case of web accessibility:

- ESOs should rapidly adopt European standards for web accessibility, following establishment of updated web guidelines (WCAG 2.0) by the World Wide Web Consortium.

- Member States should step up work on making public web sites accessible and jointly prepare for swift adoption of European web accessibility standards.

- The Commission will monitor and publish progress and may follow up at a later stage with legislative action.

State of Play: The scale of the accessibility challenge is huge and growing around $15 \%$ of Europe's population has a disability and up to one in five working-age Europeans have impairments requiring accessible solutions. Overall, three out of every five people stand to benefit from e-accessibility, as it improves general usability.

E-accessibility has socio-economic implications for both individuals and Europe as a whole. For example, accessible ICT-enabled solutions can help older workers to stay in employment and enhance the takeup of online public services such as e-Government and 
e-Health. Lack of e-accessibility excludes significant sectors of the population and prevents them from fully carrying out their professional education, leisure, democratic participation and social activities. Strengthening e-accessibility will contribute to both economic and social inclusion goals.

Many countries have adopted at least some legislative or support measures to promote e-accessibility and parts of the ICT industry are making significant efforts to improve the accessibility of their products and services.

E-accessibility is also a key element in the European e-Inclusion policy. In a broader context, ICT falls within the scope of the proposed Directive on equal treatment that refers to access to supply of goods and services available to the public. The European Commission and the Member States also have to fulfill obligations under the UN Convention on Rights of Persons with Disabilities in relation to accessibility of ICT goods and services. Some pieces of EU legislation already directly or indirectly address e-accessibility issues.

Rationale for Further Action: Despite the benefits and political attention progress in e-accessibility is still unsatisfactory. There are many striking examples of accessibility deficits, such as text relay services, essential for deaf and speech-impaired people, are only available in half of the Member States; emergency services are directly accessible by text telephone in only seven Member States, broadcasting with audio description, subtitled TV programming and TV sign-language programming remains very poor; only $8 \%$ of ATMs installed by the two main European retail banks provide "talking output."

The existing EU program relating to e-accessibility is limited. At Member State level, there is considerable fragmentation in the treatment of e-accessibility, both in the issues addressed (usually fixed telephony services, TV broadcast services and public website accessibility) and the completeness of policy instruments used. Faced with divergent requirements and uncertainties, the ICT industry suffers from this market fragmentation, making it difficult to achieve economies of scale necessary to sustain widespread innovation and market growth. Parts of the industry are actively engaged and cooperating with users (e.g. on accessible digital television) but too many are watching from the sidelines.

\section{Proposed Actions}

(1) Delivering the Change - strengthening policy priorities, coordination and stakeholder cooperation.

At European level several activities have been put in place in recent years. To support and strengthen coherence and effectiveness of a common approach and to help define priorities, the Commission will establish an ad hoc high-level group on e-accessibility, reporting to the i2010 high level group, involving consumer organizations and representatives of disabled and elderly users, ICT and assistance technology and service industries, academics and relevant authorities.

(2) Monitoring Progress and Reinforcing Good Practice.

The Commission will launch a study in 2009 to continue monitoring general e-accessibility and web accessibility progress and implementation, following up two studies conducted n 2006-2008. Under the 2009 Competitiveness and Innovation Program (CIP), the Commission will propose a new thematic network on e-accessibility and web accessibility to further enhance stakeholder cooperation in building up of experience and collection of good practice. It will also seek to reinforce the ePractice good practice exchange network on e-Government, e-Health and e-Inclusion, which has already amassed a vast amount of expertise on e-accessibility.

(3) Supporting Innovation and Deployment.

There is already extensive support for e-accessibility research and innovation in 2008. 13 new projects were funded with some Euro 43 million from the EU research program. The Commission will continue to actively support e-accessibility and ICT for independent living of elderly people through the EU research programs with a further call for proposals in 2009.

Member States and the Commission will use the Ambient Assisted Living joint research program launched in 2008 to stimulate innovative ICT-based solutions for independent living and the prevention and management of chronic conditions of elderly people.

(4) Facilitating Standardization Activities.

The Commission continues its strong support for eaccessibility in its standardization work program. In particular, Mandate 376 issued to the European Standardization Organization is an important standardization activity to foster e-accessibility. The Commission 
will promote the use of the results from this standardization work and will seek a rapid continuation of Mandate 376 to deliver the actual standards and related conformity assessment schemes. This process will be complemented and supported by stakeholders' dialogue, exchange of good practice and deployment pilots, as referred to in proposed actions of the Commission.

(5) Exploiting Current and Considering New Legislation.

There is a clear correlation at national level between the existence of legislation and the actual level of progress on e-accessibility. Research points to the risks of legal fragmentation in the EU due to divergent legislative measures. Based on this, and building on the 2005 and 2007 Communications, the Commission has started exploring a more general legislative approach to e-accessibility.

However, given the vast, complex and evolving nature of the e-accessibility field, there is not yet a clear consensus on possible EU legislation decided to eaccessibility, e.g. on elements such as scope, standards, compliance mechanisms and links to existing legislation. Furthermore, although there is a clear consensus on the need to act jointly to improve e-accessibility, there are different views on the next priorities to address. The Commission has therefore concluded that the time is not yet right for a specific e-accessibility legislative proposal, but will continue to assess its feasibility and relevance, talking into account actual progress in the field.

\section{Proposed Actions}

The primary responsibility for improving web accessibility rests with Member States and individual service providers. Nevertheless, there are actions that the Commission can undertake or facilitate that will help accelerate the improvement of web accessibility. Overall success will be achieved through a common and consistent approach. The key action areas are:
(1) Facilitate the rapid adoption and implementation of international guidelines in Europe.

There is broad consensus that WCAG 2.0 guidelines are the technical specifications to be closely adhered to for web accessibility. Once $\mathrm{W} 3 \mathrm{C}$ reaches agreement on the guidelines, expected in the near future, Mandate 376 will be able to complete its harmonization work at the European Level. In the meantime, Member States should undertake actions to ensure the Riga target for accessible public websites is achieved and prepare for the rapid incorporation of new web-accessibility specifications into national rules in a common and coherent way by:

Publishing during 2009-2010 updated technical guidance and, where appropriate, translating relevant W3C specifications; and Identifying during 2009 the public websites and intranets concerned and achieving their accessibility by 2010 .

(2) Improve the Understanding of and Promote Web Accessibility

There is a strong need for increased visibility, understanding and awareness of the needs and solutions for web accessibility. Member States should take a leading role in achieving this by:

- Widely promoting accessibility of websites by providing clear information and guidance on website accessibility, including assistive technologies, and encouraging the use of accessibility statements;

- Supporting training schemes, knowledge sharing and good practice exchange;

- Purchasing accessible tools and websites on their public procurement;

- Assigning a national contact point for web accessibility, e.g. via a website in 2009 , and

- Monitoring and reporting progress on compliance, user satisfaction and implementation costs for web accessibility on both public and other websites to the proposed high-level group and general public. 